\title{
English Teaching Strategies Based on the Combination of Schema Theory and Context Theory
}

\author{
Yan Liu \\ School of Humanities and International Education \\ Xi'an Peihua University \\ Xi'an 710125 China
}

\begin{abstract}
Schema theory considers reading is an interactive process, it emphasizes the importance of the reader's background knowledge in understanding the text. As the background knowledge is essential for the relevant schema that the reader to understand the text, context theory should be focused on the high-level structure of discourse. Only through analyzing the cohesiveness, coherence, and context in the discourse, emphasizing the combination of language, cultural and psychological factors can ensure a correct understanding of the text. This paper analyzed the theoretical background of schema theory and context theory and its implications for English reading teaching. It also illustrated the practical application of these theoretical results in English reading teaching and proposed the combination of schema theory and context theory. This was of great significance for promoting college English reading teaching.
\end{abstract}

Keywords-schema theory; context theory; English reading teaching

\section{INTRODUCTION}

Schema theory was first proposed by the German philosopher Kant. Schema theory holds that schema is an active organization of past responses or past experiences, and it is also a process in which learners receive information and learn new knowledge. That is, the schema is stored in the brain, and when it encounters a situation similar to the previous storage experience, the schema is activated and can be repeatedly memorized or updated [1]. Reading is not a process of passively accepting information, but a process of selecting, processing, and processing information based on past experience and experience. In college English reading teaching, the use of schema theory can effectively help students to establish a schema structure that matches previous experience, which can improve the effectiveness of reading.

In ancient Western society, Aristotle was the first to study the context. He believed that the environment in which language is used played a crucial role in the interpretation of the meaning of words. He once said in "Tool Theory": "A noun has many special meanings or only one meaning." "The difference between them belongs to the category or to the term. "The concept of "context "was first proposed by Malinowski, who thought "discourse was closely related with the context, which was indispensable", and Firth in 1950 added "Situation context ", namely the relationship between the language and social environment besides the context. Halliday, as a representative of systematic-functional linguistic, put forward "register ", including field, tenor, and mode. Hu Zhuanglin in 1994 developed Halliday's concept of context into three categories, namely the context, the situational context, and the cultural context. When the Master is saying, then people will not tire of words." Recently Arthur proposed "Cognitive Context", considering the constructing the context as the discourse deriving. These views can be said to be the germination of the study of context theory. With the development of linguistics, people's research on contextual issues has become more and more in-depth, more and more detailed and specific, and even the trend of "contextual theory" has emerged [2].

This paper first analyzed the theoretical background of schema theory and context theory and its implications for English reading and vocabulary teaching and also illustrated the practical application of these theoretical results in English reading and vocabulary teaching. This paper also proposed a teaching strategy that combined schema theory with context theory. This was of great significance for promoting college English reading teaching. At the same time, this study conducted an intervention study on English teaching in colleges. Through the setting of experimental group and control group, it was explored the influence of schema English teaching strategies and contextual fusion teaching on students' English reading comprehension scores and vocabulary comprehension scores.

\section{THE APPLICATION OF CONTEXT THEORY AND SCHEMA THEORY IN ENGLISH VOCABULARY TEACHING}

\section{A. Lexical context and schema teaching}

The word polysemy is a common phenomenon in the use of English. Malinowski (1923) pointed out the contextual decision-making point of view: Context is the only factor that determines the meaning of a word. It is meaningless to leave the context. Thus, the meaning of the word exists in the context, and the context determines the meaning of the word. The schema theory holds that people need to mobilize the brain's schema to deal with any information from the outside world and to interpret, predict, and organize the absorption of external information according to the schema. Schema theory has strong explanatory power and generality. It has been used to explain various psychological processes and also used in English speech communication [3]. In the process of foreign 
language teaching and cross-cultural communication, the author found that the biggest reason for the pragmatic failure of Chinese students was the lack of relevant pragmatic schema knowledge in the minds of English learners in communication.

Taking "Today, on the street, there seem to be more and more children who look very fat." as an example, when the learner reads the sentence here, the word "fat" is quite familiar to them, but how should the readers understand it? From the adverb "very" before "fat", it can be inferred that in the writer's opinion about being "fat" is not good, it means something negative or overweight in the sentence, which can be confirmed in the following sentence "Perhaps they grow fat because they eat too much." So from the above analysis, it can be seen that a word with negative meanings should be used cautiously. When a teacher introduces the word "fat", he should also introduce words which have the similar meanings, such as "plump" and "chubby" in sentence context, which will form the lexical schema.

\section{B. Reading context and schema teaching}

American linguist Dwight Bolinger pointed out: "The meaning of a word depends on the entire semantic scope of the situation in which it is placed and the role of the word and other words in the same place." From this, we can see that the meaning of the words is largely determined by the context. The vocabulary is placed in the context and helps students to summarize the relevant vocabulary groups. Students can achieve the same effects in learning the words while in reading context.

Take an article Healthy Eating extracted from An Integrated Skills Course ( $2^{\text {nd }}$ Edition) as an example. In explaining this article, the teacher will introduce the words in context and in graphic presentations if necessary. Using the pictures to show what is being fat, being plump, and being chubby is a better way for students to understand and remember the expressions of these words in a contextualized environment. During the teaching process, the teacher first asks students' understanding of the word "fat" and then explores further how they understand it in the sentence context Three main parts of schema, namely, the language schema, content schema, and formal schema show the steps of how students comprehend a passage[4].

While the theory of context and schema is used in teaching vocabularies, it is also true of interpreting the structure of the passage. With the help of the passage's structure, students understand how the passage is arranged at once. The content schema contributes not only to students' reading comprehension but also to the improvement of their writing skills.

Fig.1 is the structure of the passage Healthy Eating; it shows how the writer starts the passage through a common phenomenon or facts in life. Some related vocabulary expressions are: Today; Over; include; also include; other aspects; Nowadays, and so on. From these cohesive words and expressions, structure schema is easily concluded and shown in pictures.

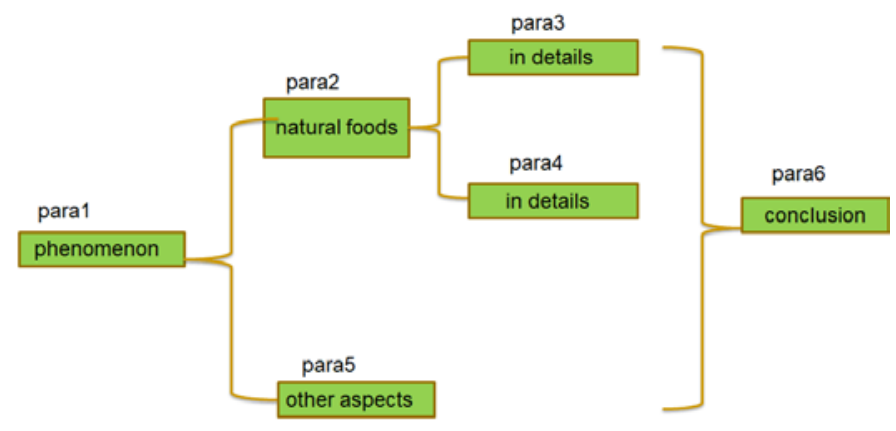

Fig. 1. The use of schema and context theory in Healthy Eating

Next is the formal schema, which means the kind of style the passage belongs to. Is it the story-telling, explanatory or argumentative. From the cohesive vocabularies, the background of the passage, and the cultural meanings of the key words and phrases, it is not difficult to infer what style the text belongs to. [5].

\section{STUdy ON THE TEACHING STRATEgy OF CONVERGENCE AND INTEGRATION OF CONTEXT THEORY AND SCHEMA THEORY-CONTEXTUALIZED THINKING TEACHING STRATEGY}

The context in the book Understanding Pragmatics (1999) is composed of communicative context and linguistic context. The lack of pragmatic schema knowledge has greatly hindered the improvement of English learners' communicative competence. We know that only when the two sides share certain knowledge, communication can proceed smoothly. Therefore, teachers need to help English learners build and expand their pragmatic knowledge in their minds. People's understanding of the world exists in the brain in the form of conceptual representation. The collection of these conceptual representations constitutes the cognitive context of thinking and understanding. When a person receives new information, it searches and invokes the concept associated with the new information to interact with the new information in this cognitive environment, thereby inferring the communicative intention of the speaker [6]. The purpose of human communication is to change others' cognition. The information provided by the speaker was not only new but also had an impact on the cognitive effect of the recipient, which created a new context. This new context is stored in the human brain in the form of conceptual representation, which becomes the potential cognitive context for future understanding. The use of schema and contextual thinking in college English teaching contributes students to construct a textual framework for reading by deconstructing textual schemas that are closely related to the text themes and forms. Combining the schema theory with the context helps learners to re-context the passage in reading class, they can not only construct the theme, content and expression of the text through "re-contextualization", but they can also enrich and improve the content and form of writing with the help of group cooperation. 
A. Designing the problem of opening up ideas, making the student's writing process "re-contextualized"

The re-cracking and recombination of the original context and the generated context is the process of recontextualization. The teacher asks the students: Why do so more and more people grow fat? Then let the students read the article again according to the following three questions, and tell the students to start organizing information from these aspects before writing:

(1) Why do so more and more people grow fat?

(2) What kinds of eating habits would affect people's weight?

(3) How much do you know about natural foods?

Through the above three questions, which can help learners open their minds, they can re-context the passage in their own way. In order to successfully replicate and apply this kind of thinking, teachers can also make students perceive the teacher's own thinking trajectory. Besides the opening-up part, the teacher provides learners related topic questions to students through the method of context and schema theory, and they also train this method in the conclusion part to recall what has been told, and especially use it to cultivate students' writing skills through raising questions, allowing students to experience living examples and "re-contextualization" of reading processes. Such as:

(1) How does the writer state the topic?

(2) In what ways does the writer use to approach the topic and how to support it?

(3) How should we be critical about the passage?

Through these kinds of questions, students would predict what will be discussed in the opening-up part and would know in depth about the passage in the conclusion part. Moreover, students' writing skills can be trained with the help of these two combined theories of schema and context. In the writing part, which is also the process of "re-contextualization", students could write an article with the words and phrases taught with the context theory and organized with the theory of schema.

\section{B. Emphasis on non-linguistic factors in discourse}

The integrity of the discourse is not only expressed in the relationship between words, sentences, paragraphs, etc. in the surface structure or structure level. It also represents the semantic center that exists in the deep structure or intent structure hierarchy. Discourse comprehension is the completion of a communicative process of semantic wholeness at the discourse level. Emphasis on the central idea, speculation, time and space order, opinion evaluation, schema chart, and mood of discourse can guide students to accurately understand and understand what they read from the perspective of the author. [7]From the choice of words which have similar meanings, teacher guide students to accurately understand what they read from the perspective of the author to reduce the bias of understanding.

\section{Improving the "pattern structure" and the function of context}

Verbal communication is not a simple static process, but a cognitive process in which the listener relies on existing knowledge and uses contextual strategies to effectively derive the meaning of the speaker's discourse. In this process, the closer the language knowledge and background knowledge stored in the brain of the listener and the speaker in the "pattern structure", the greater the ability of the listener to generate context and the better the communication effect. Therefore, the perfection of "schematic structure" is closely related to the function of context. Through comparative research, we know that the organic combination of schema theory and context theory can greatly improve the communicative effect [8]. The enlightenment of speech communication is: Verbal communication is a complex process of dynamic change. We should pay attention to the psychological factors and background knowledge of the communicator itself. In communication, the context factor should not be neglected. The speaker should try to see what the person is saying. The recipient should make correct reasoning based on the known information to achieve the effect of perfect communication.

Taking the following as an example:

Teacher: From this sentence, what can we know the meaning of "fat"?

Student: From the contexts, the use of "fat" implies that the writer holds negative attitudes about this phenomenon.

Teacher: Which part gives you this conclusion?

Student: From the topic "Healthy Eating", we can know they grow fat because of unhealthy eating.

Teacher: So can you guess what this word means: Student: It may mean "overweight".

\section{APPLICATION EXAMPLES OF SCHEMA THEORY AND CONTEXT THEORY IN ENGLISH READING TEACHING}

\section{A. Classification of experimental group and control group}

This study took students from a 2018 language school in a university as an example. The freshmen were divided into Class A and Class B according to the level of English scores, and the average scores of the two classes differ by 13.1 points. The experimental class was composed of 50 English translation majors in Class B; the remaining 55 students from a control class. The experimental class used the combination of the schema teaching method and the contextual teaching method to teach, while the control class used the conventional teaching method, such as the bottom-up Model and Interactive Model. There are 6 monthly exams and 2 final exams in two semesters. At the same time, simultaneously monitoring student learning dynamics. The monthly and final exam papers were taken out of the test bank, strictly disciplined and sealed to ensure the fairness and effectiveness of the results.

\section{B. Procedures for teaching practice}

The experimental class teachers made sufficient preparations before the semester such as the characteristics of schema theory and contextual teaching methods, the schema teaching and contextual teaching method plans, and stepped to 
carry out the methods of schema teaching and contextual teaching methods. According to the reading theory and contextual reading, the reader's reading ability was determined by language schema, content schema, formal schema, disambiguation and language ambiguity, interpretation function and so on. Therefore, in the teaching, the main focus was on the establishment, consolidation and development of the three schemas of students, whereas the context method was used to make up the shortage of language schema in teaching vocabulary.

\section{1) Consolidating language schema and context.}

Language schema is the basis of content schema and formal schema. The establishment of language schema is very important for foreign language learning. Because language is the weakest link for students to master foreign languages, and language is the medium for transmitting information. Without the corresponding language schema, we can't identify the words, phrases, and sentences in the article and also can't use the information and clues provided by the article to link with the content schema and formal schema in the brain. Therefore, it is important to teach students vocabularies in a context. Additionally, vocabulary teaching should be guided in the theory of schema to stress the cultural meaning and subtle differences between words with similar meanings. Take the word "fat" for an example, which has a similar meaning as the other two words "plump" and "chubby", but they have subtle differences. When the teacher introduces the common word "fat", which should be introduced in a sentence, and then induces "plump" and "chubby" in sentences to form a language schema to let students more clearly about their usage differences? Besides the cultural meaning of word "fat" in English, the teacher can also link it with the Chinese concept of "fat", and make a content schema to make a cultural contrast or comparison between the usage differences between Chinese and Americans. Therefore, the consolidation of language schema and context will be of great help to students' future language understanding and reading comprehension.

2) Creating structural schemas and contextual changes

According to Richards et al., the schema is the macrostructure of the discourse and the underlying structure that constitutes the discourse. Reading comprehension is not only influenced by the language and content of the article, but also by the structure of the article. Certain content often requires a specific structure to be effectively expressed [9]. As a passage is always written according to a structure, or we called writing skills, so a teacher interprets the passage from the perspective of structure to let students know clearly about the structural schema to comprehend the passage at a macro level. Language has both the time and place to help us confirm the occurrence of the words and the ability to help us connect the words to events outside the situation. This is the understanding of the contextual function of the English linguist Lyons. During the reading process, students can understand the general meaning of the article and the logical relationship between the paragraphs if the corresponding formal schema and context environment are invoked.

\section{Experimental results and analysis}

It can be seen from Table-1 that the reading comprehension scores of the experimental class have been steadily rising during the two semesters. The main reasons for the analysis are as follows: First, the teaching methods of schema training and context training played an important role; secondly, through one year of university study, students' performance was naturally improved. In order to study the effect of the above two factors, we must further compare the gap between the experimental class and the B class average, and the gap with the A-class average.

TABLE I. ENGLISH TEST SCORES FOR THE FIRST YEAR OF THE EXPERIMENTAL CLASS AND CONTROL CLASS

\begin{tabular}{|c|c|c|c|}
\hline Semester & Examinations & $\begin{array}{c}\text { Experimental class } \\
\text { scores }\end{array}$ & $\begin{array}{c}\text { control class } \\
\text { scores }\end{array}$ \\
\hline \multirow{4}{*}{ First semester } & Monthly test 1 & $76.9 \pm 1.2$ & $80.4 \pm 0.5$ \\
\cline { 2 - 4 } & Monthly test 2 & $89.6 \pm 0.9$ & $85.2 \pm 0.9$ \\
\cline { 2 - 4 } & Monthly test 3 & $92.4 \pm 0.7$ & $79.4 \pm 0.6$ \\
\cline { 2 - 4 } & Final exam & $90.6 \pm 1.2$ & $83.1 \pm 1.5$ \\
\hline \multirow{3}{*}{$\begin{array}{c}\text { Second } \\
\text { semester }\end{array}$} & Monthly test 1 & $93.4 \pm 0.5$ & $80.4 \pm 0.4$ \\
\cline { 2 - 4 } & Monthly test 2 & $90.7 \pm 0.7$ & $84.1 \pm 1.0$ \\
\cline { 2 - 4 } & Monthly test 3 & $95.4 \pm 0.9$ & $78.2 \pm 0.9$ \\
\cline { 2 - 4 } & Final exam & $94.8 \pm 1.1$ & $81.3 \pm 0.7$ \\
\hline
\end{tabular}

It can be seen from the results in Table $\mathrm{I}$ that the experimental class originally belonged to the class with poor grades in class B. There was still a difference of 5 points in the first monthly test distance from the B class average. However, after two-semester efforts, that was at the end of the first school year, the average score of reading comprehension in the experimental class exceeded the average score of reading comprehension in Class B. At the same time, the gap between the average scores of reading and understanding in Class A was also decreasing. This showed that college English teaching strategies combined with schema theory and context theory were conducive to students' English learning.

\section{CONCLUSION}

It can be clearly seen that the training of schema training and contextual cognition was indeed helpful to improve the reading level of students with poor grades. In order to enable students to quickly and efficiently grasp reading skills and methods in reading training, teachers should consider expanding the schema structure and context information in the actual teaching process, improve reading strategies and improve metacognition level, combine with teaching research and practice. Integrating vocabulary teaching into real context can stimulate students' interest in learning English and improve their vocabulary skills. It also has a great role in promoting English teaching in colleges and universities. All in all, all teaching methods are means, and they serve the purpose of improving students' English communication skills. Only by keeping this in mind can we not deliberately "take" the methods, so that the center of classroom teaching will not be biased. In other words, in the practice of teaching, we must implement the practical teaching of the teaching content according to the actual situation of the students, and finally achieve the purpose of cultivating students to use the language skillfully. 


\section{REFERENCES}

[1] MA Wei-xin. Vocabulary Teaching in the Context of Northwest University for Nationalities [J].Sino-US English Teaching, 2011, 8(7).15.

[2] Khodadady E, Hesarzadeh R. The Effect of Schema-vs-translation-based Teaching on Learning English in High Schools [J]. Theory \& Practice in Language Studies, 2014, 4(1).143-154

[3] Xi Naichao. Application of Context Theory in English Vocabulary Teaching in the Secondary Vocational School [J]. Overseas English, 2017,(10):229-230

[4] Zhao X, Zhu L. Schema Theory and College English Reading Teaching [J]. English Language Teaching, 2012, 5(11): 111-117.

[5] Skehan P. A Cognitive Approach to Language Learning[M]. 1999.
[6] Liu Y. An Empirical Study of Schema Theory and Its Role in Reading Comprehension [J]. Journal of Language Teaching and Research, 2015, 6(6): 1349-1356.

[7] Sun F. The application of schema theory in teaching college English writing [J]. Theory and Practice in Language Studies, 2014, 4(7): 1476.

[8] Jing-Schmidt Z. The place of linguistics in CSL teaching and teacher education: Toward a usage-based constructionist theoretical orientation [J]. Journal of the Chinese Language Teachers Association, 2015, 50(3): $1-22$.

[9] Wright K L, Franks A D, Kuo L J, et al. Both theory and practice: Science literacy instruction and theories of reading [J]. International Journal of Science and Mathematics Education, 2016, 14(7): 1275-1292. 